\title{
Identification and Localization of the Fatty Acid Modification in Ghrelin by Electron Capture Dissociation
}

\author{
Ziqiang Guan \\ Molecular Profiling Proteomics, Merck Research Laboratories, Rahway, New Jersey, USA
}

\begin{abstract}
Electron capture dissociation (ECD) has been demonstrated to be an effective fragmentation technique for characterizing the site and structure of the fatty acid modification in ghrelin, a 28-residue growth-hormone-releasing peptide that has an unusual ester-linked $n$-octanoyl (C8:0) modification at Ser-3. ECD cleaves 21 of 23 possible backbone amine bonds, with the product ions ( $c$ and $z \cdot$ ions) covering a greater amino acid sequence than those obtained by collisionally activated dissociation (CAD). Consistent with the ECD nonergodic mechanism, the ester-linked octanoyl group is retained on all backbone cleavage product ions, allowing for direct localization of this labile modification. In addition, ECD also induces the ester bond cleavage to cause the loss of octanoic acid from the ghrelin molecular ion; the elimination process is initiated by the capture of an electron at the protonated ester group, which is followed by the radical-site-initiated reaction known as $\alpha$-cleavage. The chemical composition of the attached fatty acid can be directly obtained from the accurate Fourier transform ion cyclotron resonance (FTICR) mass measurement of the ester bond cleavage product ions. (J Am Soc Mass Spectrom 2002, 13, 1443-1447) (c) 2002 American Society for Mass Spectrometry
\end{abstract}

$\mathrm{E}$ lectron capture dissociation (ECD) [1-5] has emerged as a promising new tool for tandem mass spectrometry (MS/MS) of multiply charged (protonated) proteins and peptides generated by electrospray ionization (ESI) [6] using Fourier transform ion cyclotron resonance (FTICR) mass spectrometry [7, 8]. ECD typically causes extensive fragmentation of backbone amine bonds to produce $c$ and $z \cdot$ fragment ions, in contrast to the $b$ and $y$ fragment ions produced from the amide bond cleavage by conventional energetic fragmentation methods, such as collisionally activated dissociation (CAD) [9-14], surface-induced dissociation (SID) [15], infrared multiphoton dissociation (IRMPD) [16], blackbody infrared dissociation (BIRD) [17, 18]. Although $c$ and $z \cdot$ ions were initially observed in the 193 $\mathrm{nm}$ ultraviolet photodissociation (UVPD) mass spectra of multiply charged protein ions [19], they were the products of unexpected ECD processes: The low-energy electrons were ejected from metal surfaces by $193 \mathrm{~nm}$ photons $(6.4 \mathrm{eV})$, and were captured by the protein ions trapped in a FTICR cell [1]. In addition, ECD is a nonergodic process (i.e., cleavage happens prior to energy randomization); the ECD backbone cleavages impart very little internal energy into the fragments, as

Published online November 7, 2002

Address reprint requests to Dr. Z. Guan, Merck Research Laboratories, P.O. Box 2000, RY50-105, Rahway, NJ 07065, USA. E-mail: ziqiang_guan@ merck.com a result, the labile side-chain modifications can be retained on the backbone fragment ions. This is in sharp contrast to the conventional ergodic fragmentation methods that typically eject the labile modifications before cleaving the backbone bonds. These unique attributes of ECD in providing extensive, nonergodic peptide backbone fragmentation have been demonstrated to be advantageous for localizing labile posttranslational modifications, such as $\gamma$-carboxylation [20], sulfonation [20], glycosylation [21-23], and phosphorylation [24, 25].

In this study we examine ECD of ghrelin, a posttranslationally acylated peptide hormone that has an unusual C8:0 acylation (octanoic acid modification) at Ser-3 residue [26, 27]. The ester-linked C8:0 fatty acyl moiety is essential for the activities of ghrelin, which include growth hormone secretion, feeding regulation, and energy homeostasis. Although the mechanism by which the fatty acyl moiety exerts its effects has not been elucidated, the hydrophobic acyl chain has often been recognized to be important for the stable association of proteins/peptides with cellular membranes [28, 29]. In determining the site and identity of the fatty acid modification in ghrelin, Kojima et al. used procedures including Edman degradation, complementary DNA analysis, ESI-MS, chemical synthesis and reverse phase HPLC analysis, which required a significant amount (micrograms) of purified materials [26]. We show here that the unique combination of extensive structural 
fragmentation by ECD and accurate mass measurements by FTICR allows for direct determination of the site and identity of the fatty acyl modification in ghrelin. The ECD results are also compared with the data obtained by CAD.

\section{Experimental}

Ghrelin (human) and des-octanoyl ghrelin (human) were purchased from Phoenix Pharmaceuticals, Inc. (Belmont, CA). Samples were dissolved in water/methanol/acetic acid (49:49:2 vol/vol/vol) at a concentration of $5 \mu \mathrm{M}$, and were nanosprayed [30] from the PicoTips (New Objective, Inc., Woburn, MA).

To perform ECD experiments, the 3-tesla Finnigan NewStar Fourier transform ion cyclotron resonance mass spectrometer (Finnigan FT/MS, Bremen, Germany) was modified. The electron gun assembly on the commercial instrument was taken out and installed in the fringing magnetic field region $(\sim 0.8 \mathrm{~m}$ away from the ICR cell) on the side opposite to that of the ESI source. Ions generated by nanospray were externally accumulated outside of the magnet in a rf-only octopole for $1 \mathrm{~s}$ and then transferred through electrostatic lenses into the trapped ion cell [31]. The precursor $[\mathrm{M}+5 \mathrm{H}]^{5+}$ ions were first isolated by stored-waveform inverse Fourier transform (SWIFT) ejection [32]. After a short pulse of $\mathrm{N}_{2}$ collision gas for ion cooling, the isolated [M $+5 \mathrm{H}]^{5+}$ ions were then irradiated with low-energy $(0.5$ $\mathrm{eV})$ electrons from the heated filament of the electron gun for $1 \mathrm{~s}$. The product ions were then subjected to chirp excitation and broadband detection. All ECD spectra shown in this paper represent an average of 50 time-domain transients obtained with an Odyssey data system.

For CAD, the SWIFT-isolated precursor ions were collisionally activated using $\sim 20 \mathrm{~V}_{p-p}$ sustained offresonance irradiation (SORI) $[14,33]$ at $-1.5 \mathrm{kHz}$ offresonance from the frequency of precursor ion, $0.1 \mathrm{~s}$ after the pulsed introduction of $\mathrm{N}_{2}$ collision gas (a peak pressure reached $\sim 5 \times 10^{-6}$ torr in the analyzer vacuum chamber).

\section{Results and Discussion}

\section{Localization of Acylation Site}

Electrospray ionization of ghrelin, GSS(n-octanoyl)FLSPEHQRVQQRKESKKPPAKLQPR, yielded an intense peak at $m / z 675$ for $[\mathrm{M}+5 \mathrm{H}]^{5+}$. Figure 1 a is the ECD spectrum of SWIFT-isolated $[\mathrm{M}+5 \mathrm{H}]^{5+}$ of ghrelin. The observed $17 c$ and $17 z$ ions correspond to the cleavage of 21 out of 23 possible backbone amine bonds. The $\mathrm{N}$-terminal sides of four prolines are not considered because they are not susceptible to cleavage by ECD due to the cyclic structure of proline (the peptide backbone would still be connected through the proline side chain even if the backbone imide- $\mathrm{N}$ to $\mathrm{C}^{\alpha}$ bond is cleaved) $[2,3]$. The mass difference of $213 \mathrm{Da}$ between

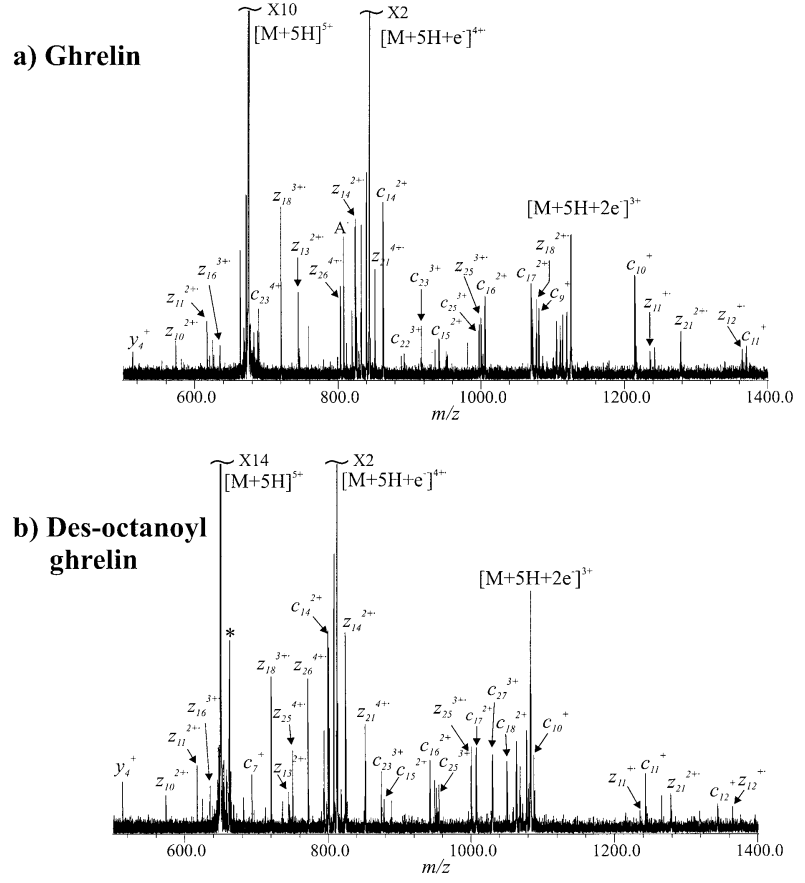

Figure 1. ECD spectra of ghrelin $[\mathrm{M}+5 \mathrm{H}]^{5+}$ and des-octanoyl ghrelin $[\mathrm{M}+5 \mathrm{H}]^{5+}$. Asterisk denotes an adduct peak not removed by SWIFT excitation.

$z_{25}{ }^{3+\cdot}\left(\mathrm{m} / \mathrm{z}\right.$ 999.5) and $z_{26}{ }^{4+\cdot}(\mathrm{m} / \mathrm{z}$ 803.2) corresponds to the mass of a C8:0 acylated serine, which permits the localization of the acylation site at Ser-3. The esterlinked C8:0 fatty acyl group is retained on all backbone fragment ions ( $c$ and $z \cdot$ ) that originally contain the acylated Ser-3, with each of these fragments having a mass shift of $126 \mathrm{Da}$ from the corresponding fragment produced from des-octanoyl ghrelin (GSSFLSPEHQRVQQRKES KKPPAKLQPR) as shown in Figure $1 b$. The retention of the ester-linked C8:0 acyl group on the backbone fragments during the ECD process supports the nonergodic mechanism, and is in agreement with previous ECD results on other labile posttranslational modifications [20-25]. The ECD spectra of ghrelin and des-octanoyl ghrelin are very similar with respect to the backbone fragmentation, perhaps implying that there is little interaction between the peptide backbone and the hydrophobic C8:0 acyl chain.

\section{$E C D$ versus $C A D$}

Sustained off-resonance irradiation (SORI) is an efficient and frequently used CAD method for tandem MS of multiply charged peptides and proteins in FTICR [14, 33]. SORI-CAD of ghrelin $[\mathrm{M}+5 \mathrm{H}]^{5+}$ yielded two $b$ and $12 y$-fragments (Figure 2a), cleaving 12 inter-residue bonds, far fewer than the 21 inter-residue bonds cleaved by ECD. The comparison of backbone cleavages effected by ECD and CAD of ghrelin $[\mathrm{M}+5 \mathrm{H}]^{5+}$ is shown in Figure 3. The major CAD product ions $\left(y_{22}-y_{26}\right.$ ion series) of ghrelin and desacyl ghrelin are produced from fragmentations near the N-terminal region. In 

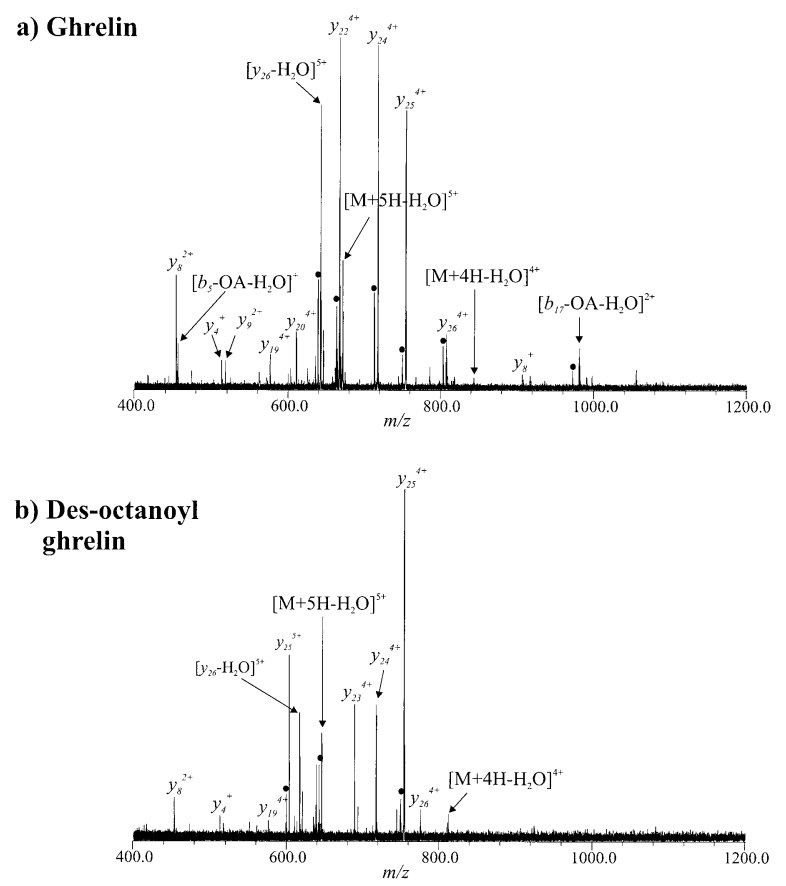

Figure 2. SORI CAD spectra of ghrelin $[\mathrm{M}+5 \mathrm{H}]^{5+}$ and desoctanoyl ghrelin $[\mathrm{M}+5 \mathrm{H}]^{5+}$. Dot denotes $\mathrm{H}_{2} \mathrm{O}$ loss peaks. OA is the abbreviation for octanoic acid.

comparison, the backbone fragmentation by ECD is far less selective; variations in ECD product ion abundance are much less significant than those in the CAD spectrum.

Many of the CAD fragments are accompanied by structurally uninformative $\mathrm{H}_{2} \mathrm{O}$ losses, which are absent in the ECD spectra. Among the three backbone fragments $\left(b_{5}, b_{17}\right.$, and $\left.y_{26}\right)$ that contain Ser-3, the ester-linked octanoyl group is retained only on $y_{26}$, but completely lost from $b_{5}$ and $b_{17}$ ions. These neutral losses $\left(\mathrm{H}_{2} \mathrm{O}\right.$ and the $\mathrm{C} 8: 0$ fatty acid) from the backbone fragments are undesirable, and severely complicate MS/MS data interpretation. There have been few reports describing MS/MS characterization of acylated proteins or peptides. In identifying the novel palmitoyl-

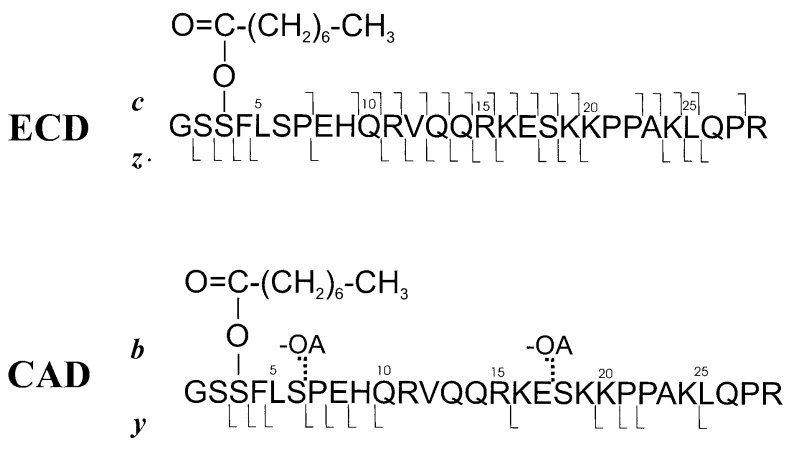

Figure 3. Comparison of backbone cleavage sites by ECD and CAD of ghrelin $[\mathrm{M}+5 \mathrm{H}]^{5+}$. ECD: The octanoyl group is retained on the backbone fragment ions ( $c$ and $z$ ions) that contain Ser-3. CAD: The octanoyl group is retained on $y_{26}{ }^{4+}$, but not on $b_{5}{ }^{+}$or $b_{17}{ }^{2+}$ ions. These fragments $\left(y_{26}{ }^{4+}, b_{5}{ }^{+}\right.$, and $\left.b_{17}{ }^{2+}\right)$ are the Ser-3 containing fragments observed in the CAD spectrum of ghrelin.

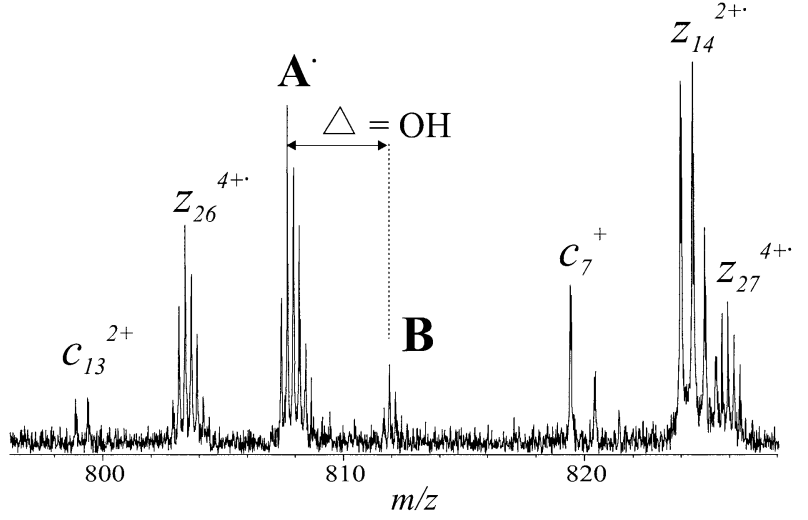

Figure 4. Expanded ECD spectrum of ghrelin. A· and B ions are product ions from the ester bond cleavage.

ations on internal lysine residues in adenylate cyclase toxins (ACT) [34, 35], Hackett and coworkers showed that the amide-linked palmitoyl groups are retained on the backbone fragments $(b, y)$ during CAD in a triplequadrupole mass spectrometer.

It is noteworthy that the FTICR-CAD spectrum of ghrelin shows far fewer $b$ ions than $y$ ions. This is perhaps due to the lower stability of $b$ type ions as suggested previously [36, 37]. Given that the CAD spectrum of desacyl ghrelin (Figure $2 b$ ) shows no $b$ ions, the fatty acid elimination in ghrelin during CAD might help to release the excess internal energy, and thus stabilize the observed $b$ ions $\left(b_{5}\right.$ and $\left.b_{17}\right)$.

The charge-reduced molecular species, $[\mathrm{M}+5 \mathrm{H}+$ $\mathrm{e}]^{4+\cdot}$ and $[\mathrm{M}+5 \mathrm{H}+2 \mathrm{e}]^{3+}$, are the major product ions in the ECD spectra of $[\mathrm{M}+5 \mathrm{H}]^{5+}$ for both ghrelin and des-octanoyl ghrelin. The charge-reduced species are not structurally informative and have often been observed as the major peaks in the ECD spectra of multiply charged proteins and peptides. However, they are absent or negligible in the CAD spectra.

\section{ECD of the Ester Bond in Ghrelin}

The expanded ECD spectrum of ghrelin (Figure 4) shows two ester bond cleavage product ions. The major peak $\mathbf{A} \cdot(+4, m / z 807)$, differing from $[\mathrm{M}+5 \mathrm{H}]^{4+\cdot}$ ion by 144.112, is consistent with the loss of a C8:0 fatty acid $\left(\mathrm{C}_{8} \mathrm{H}_{16} \mathrm{O}_{2}\right.$, theoretical mass 144.115). The minor peak $\mathbf{B}$ is $17 \mathrm{Da}$ higher in mass than $\mathbf{A}^{\cdot}$, corresponding to the loss of $\mathrm{C}_{8} \mathrm{H}_{15} \mathrm{O}$ from $[\mathrm{M}+5 \mathrm{H}]^{4+\cdot}$.

The proposed mechanisms for ECD of the ester bond to generate $\mathbf{A} \cdot$ and $\mathbf{B}$ product ions are shown in Scheme 1. Both mechanisms are based on the postulate that there is one charge (proton) localized at the ester group (the ester group is either protonated, or serves as the solvation site for the protonated side chain of a basic amino acid residue). Supporting evidence for this charge site is the charge states of C-terminal backbone fragment ions by both ECD and CAD (ECD: $z_{26}^{4+}, z_{25}^{3+*}$; CAD: $\left.y_{26}^{5+}, y_{25}^{4+}\right)$; there is one charge difference in the 

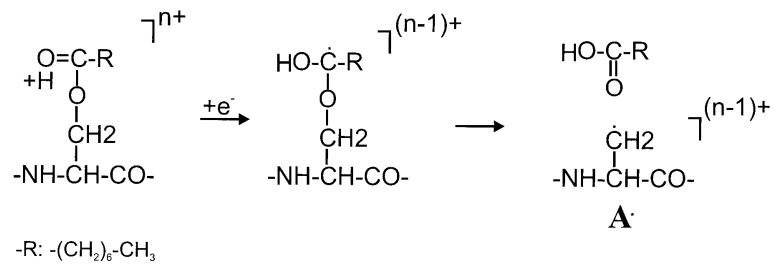

A

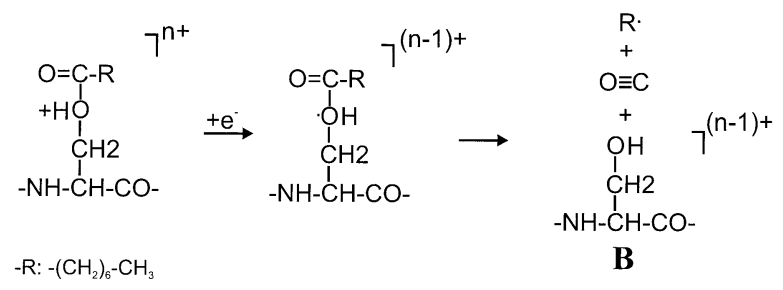

Scheme 1. Proposed mechanisms for the ester bond cleavage by ECD of ghrelin to yield product ions $\mathbf{A} \cdot$ and $\mathbf{B}$.

product ions from cleavages at the second and third inter-residue bonds. Protonation of the ester seems to be unlikely, based on the proton affinities (PA) of small molecule esters $(200-205 \mathrm{kcal} / \mathrm{mol})$ and individual amino acids (200-230 kcal/mol) [38, 39]. However, protonation of the ester (at Ser-3) is favored in terms of electrostatic forces and coulombic energy [40], because this charge site would be relatively distant from the eight most basic residues (1 histidine, 4 lysines, 3 arginines) in ghrelin, some of which are likely to be protonated in the $5+$ ions, but none is in the $\mathrm{N}$-terminal region.

The electron capture by the protonated carbonyl group yields a free radical site, which then leads to the elimination of the C8:0 fatty acid from the precursor molecular ion. This fragmentation pathway (leading to A', Scheme 1) is analogous to the radical-site-initiated reaction known as " $\alpha$-cleavage" [41, 42], and parallels the backbone amine bond cleavage leading to $c, z$. backbone fragment ions. The fragmentation pathway that yields the minor product ion (B), is similar to the pathway leading to minor $a^{*}, y$ backbone fragment ions [1-3]. The ester bond cleavage represents a new example of the radical site reactions initiated by electron capture at a protonated functional group. Previously, ECD had been reported to yield only minimal fragmentation for multiply charged polyester ions [3]. The fatty acid elimination by ECD of ghrelin is also analogous to amino acid side-chain fragmentation [1, 43], which occurs in basic residues that are likely to be protonated and capture electrons. From the fatty acid elimination products, the chemical composition of the modifying group can be determined by the accurate FTICR mass measurement. Thus, the ester bond cleavage offers direct information about the presence and structure of the fatty acid modification.

\section{Conclusion}

The current results demonstrate the applicability of ECD for characterizing an acylated peptide. ECDFTICR/MS provides sufficient structural information for identifying the chemical nature and determining the site of the fatty acid modification in ghrelin. ECD offers more extensive sequence fragmentation than $\mathrm{CAD}$, and preserves the C8:0 fatty acyl group on the backbone sequence fragment ions ( $c$ and $z \cdot$ ions) allowing for direct localization of the acylation site. Furthermore, ECD causes cleavage of the ester bond, resulting in the loss of the C8:0 fatty acid from the molecular ion. This process is postulated to be an odd-electron, free radical driven $\alpha$-cleavage. The accurate mass measurement of FTICR/MS can be utilized to determine the elemental composition and to deduce the chemical structure of the modifying fatty acid group. These results demonstrate that ECD-FTICR may find general applications in characterizing the ester-linked fatty acylations in peptides or proteins.

\section{Acknowledgments}

The author thanks Drs. Patrick Griffin, Brian McKeever, and Shilan $\mathrm{Wu}$ for helpful discussions and critical reading of the manuscript.

\section{References}

1. Zubarev, R. A.; Kelleher, N. L.; McLafferty, F. W. Electron Capture Dissociation of Multiply Charged Protein Cations. A Nonergodic Process. J. Am. Chem. Soc. 1998, 120, 3265-3266.

2. Zubarev, R. A.; Horn, D. A.; Fridriksson, E. K.; Kelleher, N. L.; Kruger, N. A.; Lewis, M. A.; Carpenter, B. K.; McLafferty, F. W. Electron Capture Dissociation for Structural Characterization of Multiply Charged Protein Cations. Anal. Chem. 2000, 72, 563-573.

3. McLafferty, F. W.; Horn, D. M.; Breuker, K.; Ge, Y.; Lewis, M. A.; Cerda, B.; Zubarev, R. A.; Carpenter, B. K. Electron Capture Dissociation of Gaseous Multiply Charged Ions by Fourier-Transform Ion Cyclotron Resonance. J. Am. Soc. Mass Spectrom. 2001, 12, 245-249.

4. Cerda, B. A.; Breuker, K.; Horn, D. M.; McLafferty, F. W. Charge/Radical Site Initiation vs. Coulombic Repulsion for Cleavage of Multiply Charged Ions. Charge Solvation in Poly(alkene glycol) Ions. J. Am. Soc. Mass Spectrom. 2001, 12, 565-570.

5. Horn, D. M.; Zubarev, R. A.; McLafferty, F. W. Automated de Novo Sequencing of Proteins by Tandem High-Resolution Mass Spectrometry. Proc. Natl. Acad. Sci. U.S.A. 2000, 97, 10313-10317.

6. Fenn, J. B.; Mann, M.; Meng, C. K.; Wong, S. F.; Whitehouse, C. M. Electrospray Ionization for Mass Spectrometry of Large Biomolecules. Science 1989, 246, 64-71.

7. Comisarow, M. B.; Marshall, A. G. Fourier Transform Ion Cyclotron Resonance [FT-ICR] Spectroscopy. Chem. Phys. Lett. 1974, 25, 282-283.

8. Marshall, A. G.; Hendrickson, C. L.; Jackson, G. S. Fourier Transform Ion Cyclotron Resonance Mass Apectrometry: A Primer. Mass Spectrom. Rev. 1998, 17, 1-36.

9. Busch, K. L.; Glish, G. L.; McLuckey, S. A. Mass Spectrometry/ Mass Spectometry. Techniques and Applications of Tandem Mass Spectrometry. VCH: New York, 1988, 333. 
10. Biemann, K.; Papayannopoulos, I. A. Amino Acid Sequencing of Proteins. Acc. Chem. Res. 1994, 27, 370-378.

11. Hunt, D. F.; Yates, J. R., III; Shabanowitz, J.; Winston, S.; Hauer, C. R. Protein Sequencing by Tandem Mass Spectrometry. Proc. Natl. Acad. Sci. U.S.A. 1986, 83, 6233-6237.

12. Loo, J. A.; Udseth, H. R.; Smith, R. D. Primary Sequence Information from Intact Proteins by Electrospray Ionization Tandem Mass Spectrometry. Science 1990, 248, 201-204.

13. McLuckey, S. A.; Wells, J. M. Mass Analysis at the Advent of the 21st Century. Chem. Rev. 2001, 101, 571-606.

14. Senko, M. W.; Speir, J. P.; McLafferty, F. W. Collisional Activation of Large Multiply Charged Ions Using Fourier Transform Mass Spectrometry. Anal. Chem. 1994, 68, 28012808.

15. McCormack, A. L.; Jones, J. L.; Wysocki, V. H. Surface-Induced Dissociation of Multiply Protonated Peptides. J. Am. Soc. Mass Spectrom. 1992, 3, 859-862.

16. Little, D. P.; Speir, J. P.; Senko, M. W.; O'Connor, P. B.; McLafferty, F. W. Infrared Multiphoton Dissociation of Large Multiply Charged Ions for Biomolecule Sequencing. Anal. Chem. 1994, 66, 2809-2815.

17. Dunbar, R. C.; McMahon, T. B. Activation of Unimolecular Reactions by Ambient Blackbody Radiation. Science 1998, 279, 194-197.

18. Price, W. D.; Schnier, P. D.; Williams, E. R. Tandem Mass Spectrometry of Large Biomolecule Ions by Blackbody Infrared Radiative Dissociation. Anal. Chem. 1996, 68, 859-866.

19. Guan, Z.; Kelleher, N. L.; O'Connor, P. B.; Aaserud, D. J.; Little, D. P.; McLafferty, F. W. 193 nm Photodissociation of Larger Multiply-Charged Biomolecules. Int. J. Mass Spectrom. Ion Processes 1996, 157/158, 357-364.

20. Kelleher, N. L.; Zubarev, R. A.; Bush, K.; Furie, B.; Furie, B. C.; McLafferty, F. W.; Walsh, C. T. Localization of Labile Posttranslational Modifications by Electron Capture Dissociation: The Case of $\gamma$-Carboxyglutamic Acid. Anal. Chem. 1999, 71, $4250-4253$.

21. Mirgorodskaya, E.; Roepstorff, P.; Zubarev, R. A. Localization of O-Glycosylation Sites in Peptides by Electron Capture Dissociation in a Fourier Transform Mass Spectrometer. Anal. Chem. 1999, 71, 4431-4436.

22. Håkansson, K.; Cooper, H. J.; Emmett, M. R.; Costello, C. E.; Marshall, A. G.; Nilsson, C. L. Electron Capture Dissociation and Infrared Multiphoton Dissociation MS/MS of an NGlycosylated Tryptic Peptide to Yield Complementary Sequence Information. Anal. Chem. 2001, 73, 4530-4536.

23. Haselmann, K. F.; Budnik, B. A.; Olsen, J. V.; Nielsen, M. L.; Reis, C. A.; Clausen, H.; Johnsen, A. H.; Zubarev, R. A. Advantages of External Accumulation for Electron Capture Dissociation in Fourier Transform Mass Spectrometry. Anal. Chem. 2001, 73, 2998-3005.

24. Shi, S. D.-H.; Hemling, M. E.; Carr, S. A.; Horn, D. M.; Lindh, I.; McLafferty, F. W. Phosphopeptide/Phosphoprotein Mapping by Electron Capture Dissociation Mass Spectrometry. Anal. Chem. 2001, 73, 19-22.

25. Stenballe, A.; Jensen, O. N.; Olsen, J. V.; Haselmann, K. F.; Zubarev, R. A. Electron Capture Dissociation of Singly and Multiply Phosphorylated Peptides. Rapid Commun. Mass Spectrom. 2000, 14, 1793-1800.
26. Kojima, M.; Hosoda, H.; Date, Y.; Nakazato, M.; Matsuo, H.; Kangawa, K. Ghrelin is a Growth-Hormone-Releasing Acylated Peptide from Stomach. Nature 1999, 402, 656-660.

27. Tschop, M.; Smiley, D. L.; Heiman, M. L. Ghrelin Induces Adiposity in Rodents. Nature 2000, 407, 908-913.

28. Towler, D. A.; Gordon, J. I.; Adams, S. P.; Glasser, L. The Biology and Enzymology of Eukaryotic Protein Acylation. Ann. Rev. Biochem. 1988, 57, 69-99.

29. Olson, E. N. Modification of Proteins with Covalent Lipids. Prog. Lipid Res. 1988, 27, 177-197.

30. Wilm, M. S.; Mann, M. Analytical Properties of the Nanoelectrospray Ion Source. Anal. Chem. 1996, 68, 1-8.

31. Winger, B. E.; Campana, J. E. Characterization of Combinatorial Peptide Libraries by Electrospray Ionization Fourier Transform Mass Spectrometry. Rapid Commun. Mass Spectrom. 1996, 10, 1811-1813.

32. Marshall, A. G.; Wang, T. C. L.; Ricca, T. L. Tailored Excitation for Fourier Transform Ion Cyclotron Mass Spectrometry. J. Am. Chem. Soc. 1985, 107, 7893-7897.

33. Gauthier, J. W.; Trautman, T. R.; Jacobson, D. B. Sustained Off-Resonance Irradiation for Collision-Activated Dissociation Involving Fourier Transform Mass Spectrometry. CollisionActivated Dissociation Technique that Emulates Infrared Multiphoton Dissociation. Anal. Chim. Acta 1991, 246, 199-210.

34. Havlícek, V.; Higgins, L.; Chen, W.; Halada, P.; Sebo, P.; Sakamoto, H.; Hackett, M. Mass Spectrometric Analysis of Recombinant Adenylate Cyclase Toxin from Bordetella pertussis strain 18323/pHSP9. J. Mass Spectrom. 2001, 36, 384-391.

35. Hackett, M.; Guo, L.; Shabanowitz, J.; Hunt, D. F.; Hewlett, E. L. Internal Lysine Palmitoylation in Adenylate Cyclase Toxin from. Bordetella pertussis. Science 1994, 266, 433-435.

36. Yalcin, T.; Csizmadia, I. G.; Peterson, M. R.; Harrison, A. G. Why are B Ions Stable Species in Peptide Spectra? J. Am. Soc. Mass Spectrom. 1995, 6, 1165-1174.

37. Aaserud, D. J.; Little, D. P.; O'Connor, P. B.; McLafferty, F. W. Distinguishing $\mathrm{N}$ - and C-Terminus Ions for Mass Spectrometry Sequencing of Proteins without Prior Degradation. Rapid Commun. Mass Spectrom. 1995, 9, 871-876.

38. Evans, J.; Nicol, G.; Munson, B. Proton Affinities of Saturated Aliphatic Methyl Esters. J. Am. Soc. Mass Spectrom. 2000, 11, 789-796.

39. Green, M. K.; Lebrilla, C. B. Ion-Molecule Reactions as Probes of Gas-Phase Structures of Peptides and Proteins. Mass Spectrom. Rev. 1997, 16, 53-71.

40. Schnier, P. D.; Gross, D.; Williams, E. R. Electrostatic Forces and Dielectric Polarizability of Multiply Protonated Gas-Phase Cytochrome $c$ Ions Probed by Ion/Molecule Chemistry. J. Am. Chem. Soc. 1995, 117, 6747-6757.

41. McLafferty, F. W.; Turecek, F. J. Interpretation of Mass Spectra; 4th ed. University Science Books: Mill Valley, 1993, 57-59.

42. Levsen, K. Fundamental Aspects of Organic Mass Spectrometry. Verlag Chemie: Weinheim and New York, 1978, 160-161.

43. Cooper, H. J.; Hudgins, R. R.; Håkansson, K.; Marshall, A. G. Characterization of Amino Acid Side Chain Losses in Electron Capture Dissociation. J. Am. Soc. Mass Spectrom. 2002, 13, 241-249. 